\title{
Study on Design Principle of Clothing Display Color
}

\author{
Wanyue $\mathrm{Hu}^{1} \&$ Yanmei $\mathrm{Li}^{1}$ \\ ${ }^{1}$ Shanghai University of Engineering Science Fashion Institute, Shanghai, China \\ Correspondence: Yanmei Li, Shanghai University of Engineering Science Fashion Institute, Shanghai, China. Tel: \\ 86-180-1765-8490. E-mail: lym0350@126.com
}

\section{Fund programs}

Shanghai University of Engineering Science innovation project "Design and implementation of virtual closet system based on mobile terminal" (E1-0903-14-01168)

Shanghai University of Engineering Science innovation project "Development of clothing network closet system based on the mobile platform" (A1-5300-14-050137)

Received: April 8, 2015 Accepted: April 26, 2015 Online Published: July 2, 2015

doi:10.5430/sass.v2n2p8 URL: http://dx.doi.org/10.5430/sass.v2n2p8

\begin{abstract}
Display color design is a very important part of visual merchandising. The article briefly introduces the concept and design category of display color design, and show its important in clothing marketing and management, then elaborate the design principle of clothing display color mainly from two aspects of clothing brand positioning and consumer psychology. Clothing brand should focus on research the color psychology and preference of target consumers after clear their own target consumers positioning, in order to better for color design of clothing and display.
\end{abstract}

Keywords: visual merchandising, display color design, brand positioning, color psychology

\section{Preface}

Visual merchandising (VMD) as a kind of product planning marketing strategy with visual as the center have been noticed by enterprise and display division in recent years (Mu \& Pan, 2014), it show the enterprise information, product information, service concept and brand culture to consumers through the display of goods, and to promote sales, improve corporate profits, setting up enterprise brand image as well (Hu, 2012). The color is the soul and core elements of display products in clothing stores, which act a important role for comfort degree, environmental atmosphere of stores and people's psychological and physiological.

Psychology research shows that all the information people accept from the outside world, there are $83 \%$ is the result of visual perception (Hu, 2012), and the color is the first element that cause visual reaction. In addition, according to the international fashion color association survey data show that by changing the design of the color, can give the added value of products from $10 \%$ to $25 \%$ (Ma \& Wang, 2006), and without any increase in costs. So, the design of the display color is very important.

\section{Introduction to Display Color Design Theory}

\subsection{Basic Concept of Display Color Design}

Clothing products display color design is start from the perspective of color, using the method of product display, to rearrange the combination of clothing products, then create a display method which conforms to the style of clothing brand and the fashion trend (Zhou, 2012).

Display color design including gradient, contrast, symmetry, echo and so on (Yang, 2012). Among them, the gradient color display design including gradient of hue and lightness, they all arranged according to certain rules formation to give person a halcyon harmony of beauty. Contrast color display design refers to choose colors that the interval on 
the hue circle is $120^{\circ}$ to deal a combination design, which contrasting and harmony and bring a visual impact to people. Symmetrical color display design is based on the center axis of symmetry, set the left and right sides equidistance positional color relations one to one correspondence, give a person the sense with stable and serious. Color echo is a method of using the same color or similar color in different location within visual range of the plane or space, which has a unified coordination of repeated rhythm beauty ( $\mathrm{Li}, 2004)$, and avoid scattered visual effect caused by large space.

\subsection{Design Category of Display Color Design}

(1) Ambient color

Ambient color including the color of the ceiling, floor, wall, closet and so on. The ambient color play a dominant and set off role to main color of display space because of its possession of a wide range. And in order to foil the color of the goods, and also conforms to the merchandise and brand positioning and style, the ambient color usually use low purity color with taller lightness.

(2) Prop color

There need to use some gorgeous or simple display props when making the display color design, in order to build the theme atmosphere of display and to foil the characteristics of products. So the color of props need to conform to the theme display color and improve reveal degree of commodity color .

(3) Lighting color

Lighting color is not only to unify or reinforce the color of display space, and also can effective foil display space environment atmosphere. Such as bright white lights make the entire store appears clean, neat feeling, the soft yellow, orange, warm lights will make consumers feel warm and relax, the cool color such as blue light, give a person the sense is relatively serious, calm. Specific how to choose lighting color is according to the style of goods and brand.

(4) Commodity color

Commodity color is the main and core part of the display color design, the color of environment, props, lighting that the above mentioned are all in order to foil the color of the goods, to express the colors charm of the commodity and the brand image better. For example, there should be used low lightness background color if the commodity color is high lightness. And if commodity color is more rich and colorful, the background color will use the no-color such as black, white and grey.

\section{Functions of Display Color Design Play in Clothing Sales and Management}

(1) Highlighting the brand image

A good display color design can bring harmony and comfortable environment to stores, and bring a good visual enjoyment and happy shopping mood to consumers, giving a good brand impression to consumers as well. Brand should have its own core tonal and uniform color style, and often replace display color design according to the need on the basis of the unified, all the above can better highlight the brand image and obtain a higher brand loyalty.

(2) Strengthening the order of stores

Feast for the eyes of display color has a certain role to enhance stores order. Harmony tonal, rich layered and rhythm of color combination can highlight the goods and make the markets show a harmonious, neat sense of order. Avoid the messy and complex which repels the consumers.

(3) Easy for customers to choose and purchase

Many stores choose to display their clothes and divide the sales area by the color scheme. Each customer has their own preference color, and they may straight to their favorite color when entering the store area, then choose the style, etc., so the good display color design is not only easy for consumers to choose and also improve the success rate of sales.

\section{(4) Easy for salesmen to manage}

The clear color design help clothing sales personnel adjusting goods order timely according to the characters of the goods' color, its facilitates the management of the store image and help to improve the work efficiency ( $\mathrm{Li}$, 2009).Generally, a clothing brand has its own display manual, which have certain guidance and constraints to the basic methods and principles of display, and also have specific requirements and guidance to colorific collocation 
and color display methods, it's convenient for sales staff to display and manage commodities in a timely manner according to the requirements.

\section{Design Principle of Clothing Display Color}

\subsection{Conform to the Brand Image and Target Consumers Positioning}

Different brand have different cognition and understanding of the terminal color because of different brand positioning, cultural background, marketing concept, target consumers, etc. (Li, 2012). So the design of the display color must conform to the image of the brand and its product and target consumers positioning.

\subsubsection{Color Core Value of the Brand}

Brand core value is the most significant characteristics for a brand to differ from others which could let customers clearly identify and remember the brand personality and interest points (Bian, 2010). Now, many brands are willing to use color to shape their brand core value, and consumers also can easily identify a brand according to the color, this is known as the color core value of brand.

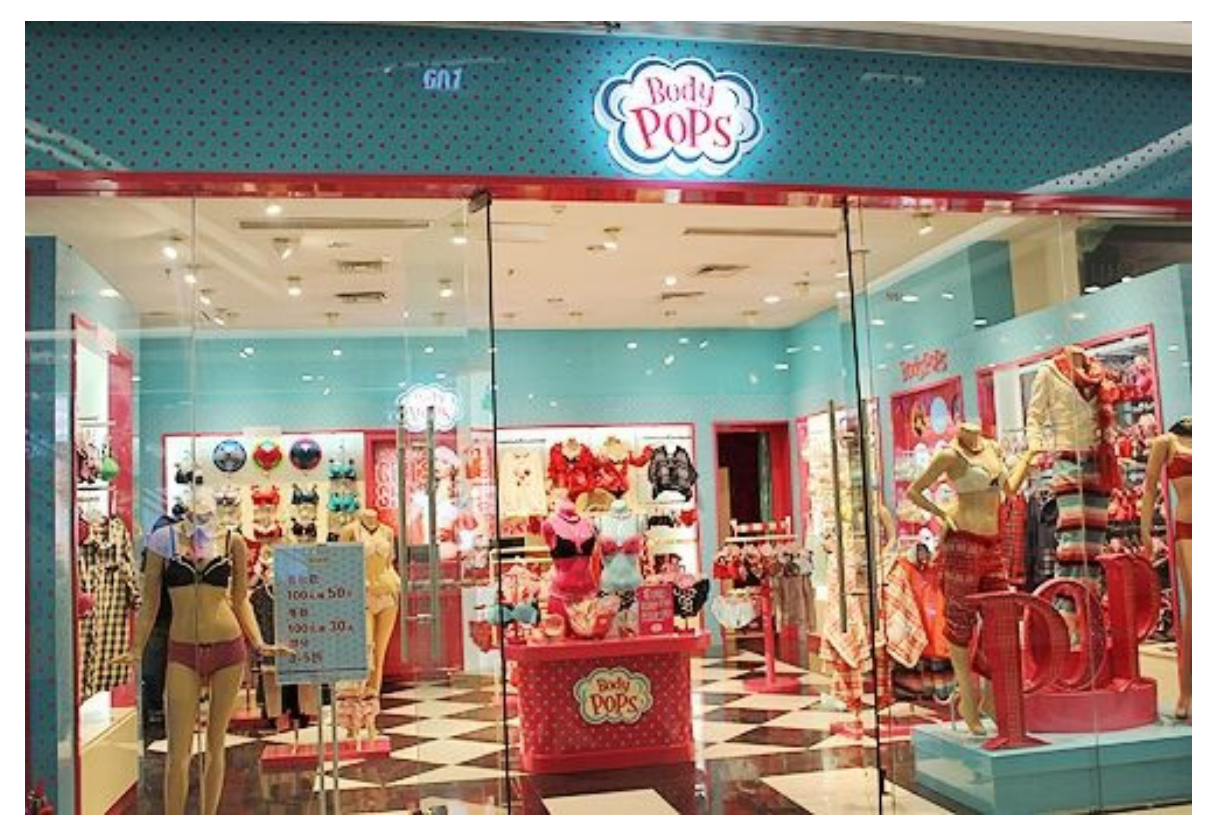

Figure 1. BODY POPS brand

As shown in fig. 1 is the young girl underwear brand BODY POPS, with the bright and strong contrast color, and nifty and lovely style. Store environment color is given priority to with tall lightness and so as the product color, add bright white light, the stores are filled with young girl lovely sexy atmosphere, make consumers may first thought of the BODY POPS when they see young girl underwear store with this kind of color. So the powder blue and pink is the color core value of the BODY POPS. 


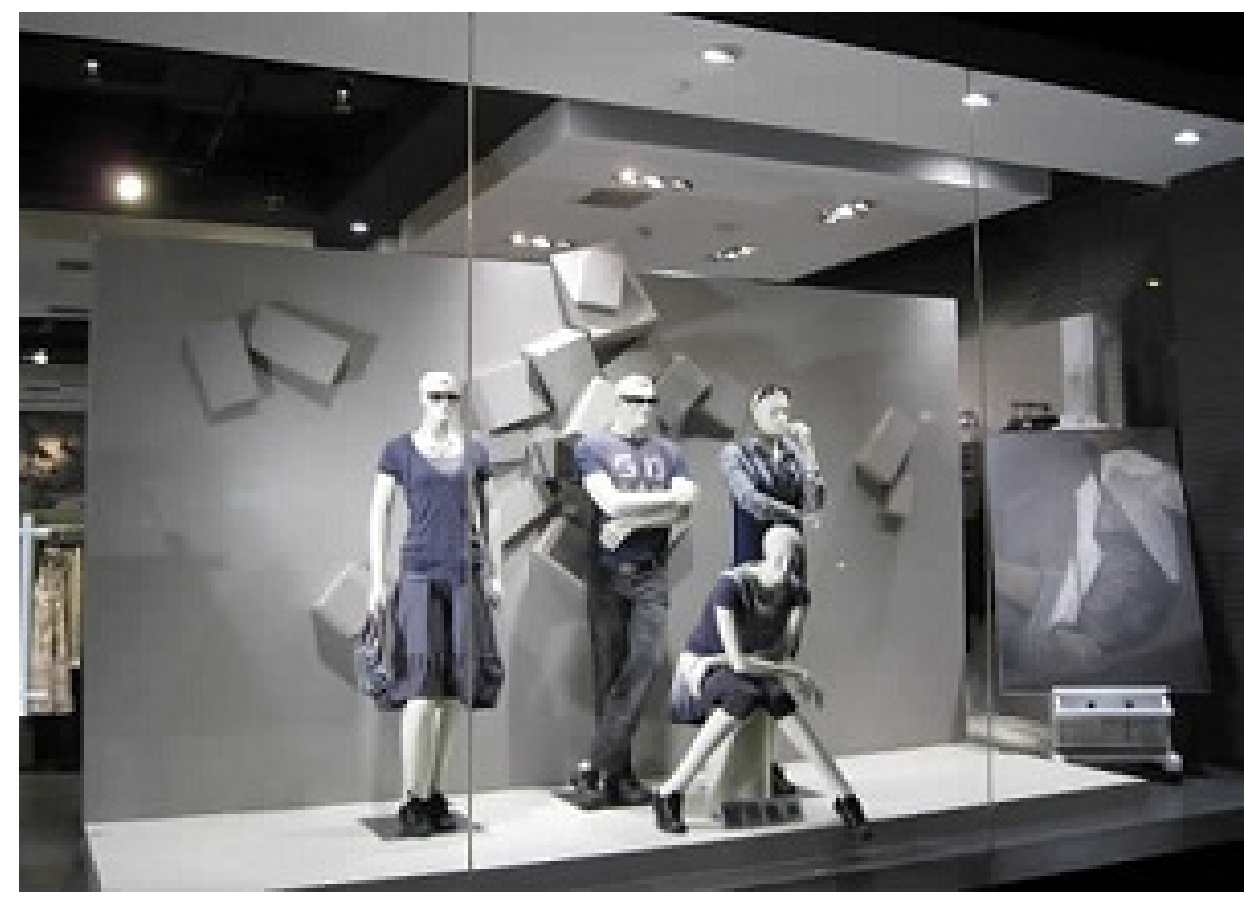

Figure 2. S.DEER brand

As shown in figure 2 is the euramerican style fashion brand S.DEER. Whether the environment color or the product itself are given priority to no-color such as black, white and grey, left a deep impression to consumers with bright lights. No-color is the color core value of S.DEER.

\subsubsection{Display Color Design and Brand Target Consumers Positioning}

With market segmentation of the apparel industry, the clothing brand positioning of target consumers also more and more clear, now in the market has almost can not exist the clothing brand that can satisfy consumer demand from 18 to 45 years old at the same time ${ }^{[1]}$. Costume designer should give full consideration to the target consumers of brand for application of color when they designing clothing, and clothing display designer should show the perfect clothing through perfect display design. From the core color selection when decorating stores, to the color of display props, to the collocation and expression of clothing color, consumers positioning of brand should been clear. Fully considering the target consumer psychology and preference, to cater their emotional pursuit, allowing consumers to find and select the object to place their rationality and emotion.

For example, children's wear color should conform to the psychological characteristics of children, they unlike adults, they are innocent and lively so have a special color preferences, such as bright red, sky blue, orange, etc. Children generally like the color of high purity, high brightness, because this kind of color can appear lively, light, and can most express warm emotion(Sun, 2013). 


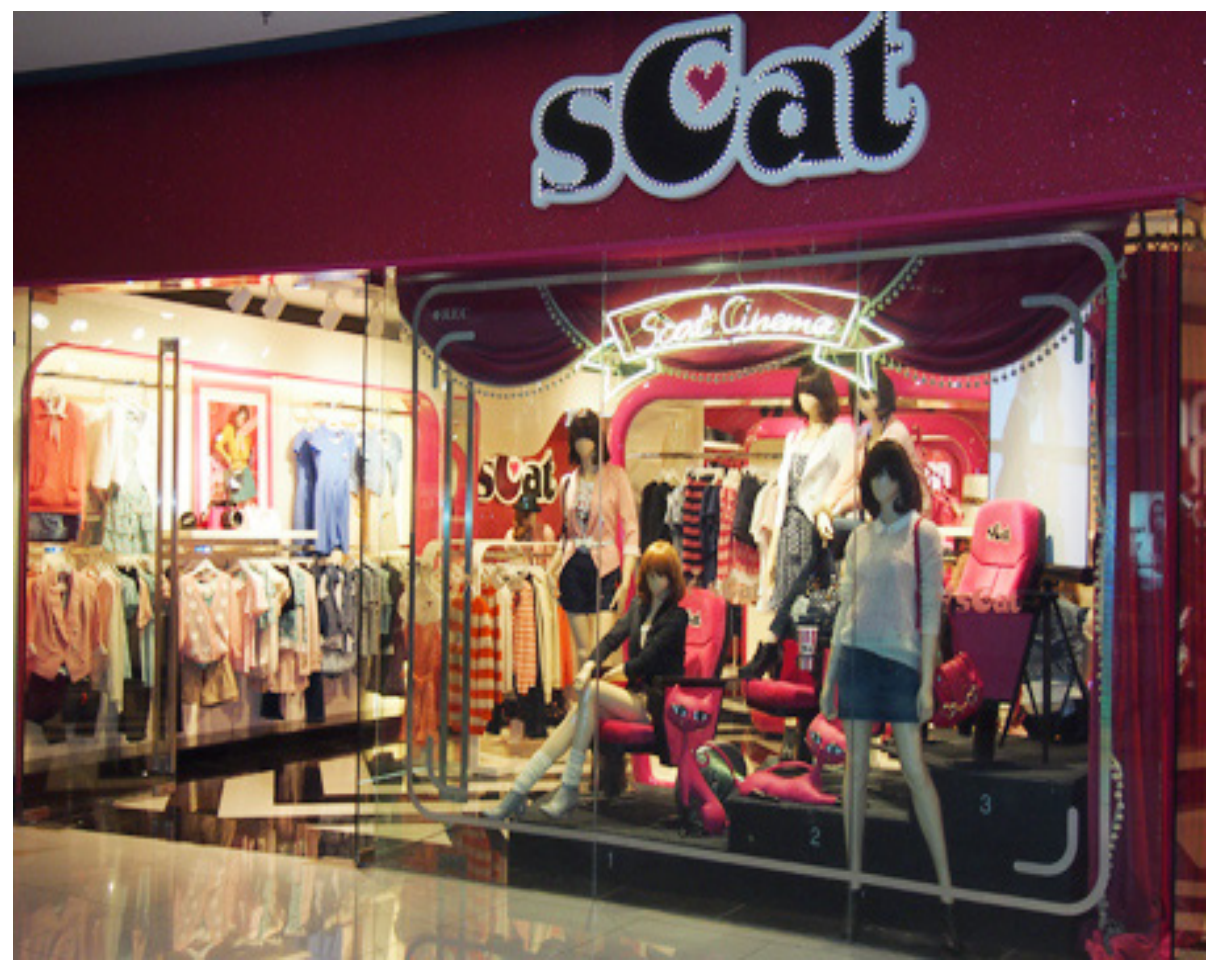

Figure 3. SCAT brand

As shown in figure 3 is leisure girls brand SCAT, namely, a collection of Sexy, Cute and Cat, locate the target consumers to 18-25 year old girl.The environment color, props color and clothing goods color are all given priority to pink, breezy lovely girl brand image are reflected.

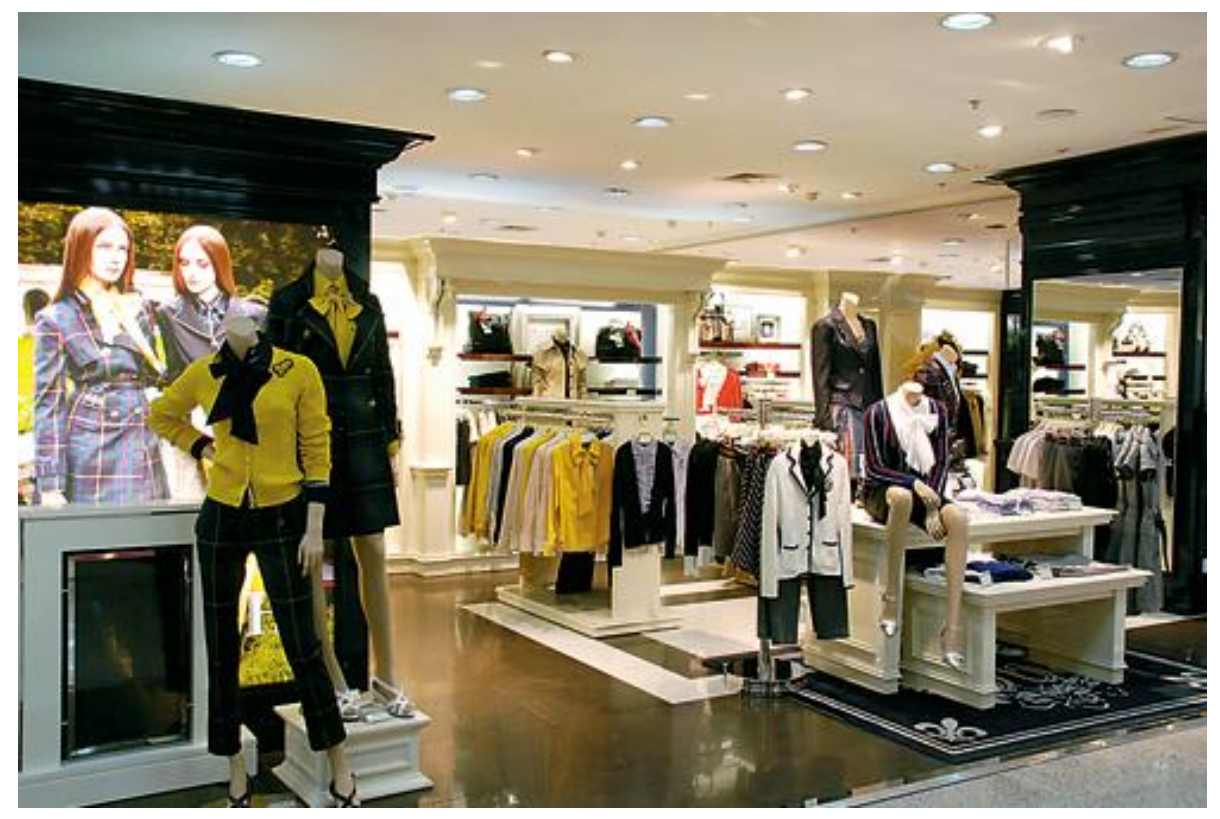

Figure 4. PRICH brand 
As shown in Fig. 4 is women's clothing brand PRICH with American style, its target consumers locate to 25 to 35 years old urban white-collar female. Clothing and store coloring decent, simple but not rigid, modern but not frivolous, meet the emotional pursuit that concise but not break interest of young career women.

\subsection{In Accordance with Consumer Psychology and Preference}

People have different selection of clothing color because they living and working in different environment, everyone has different coloring habits because of different living environment, occupation, personality, age, etc, of course, their preference color will change with the change of these conditions. The brand should have a corresponding display color design according to different consumers with different psychological and preferences.

\subsubsection{Color Psychology}

When clothing color effects on people's visual sense, there will be associated with experience of life and environmental affairs due to visual stimuli, which is called color psychological feelings. Each color give people different mental feelings because of its different symbolic significance, as shown in table 1.Even the same color, but because of the difference of its purity, lightness, also produced the different psychological effect(Tian \& Wang, 2008).

Table 1. mental feelings of colors

\begin{tabular}{c|c}
\hline color & Mental feelings \\
\hline red & enthusiastic, ebullience, happy, dynamic \\
\hline orange & cozy, optimistic, sunny, healthy \\
\hline yellow & young, bright, dazzling, exciting \\
\hline green & life, hopeful, safe, natural \\
\hline blue & calm, rational, quiet, wide \\
\hline purple & romantic, kingly, visional, mysterious \\
\hline black & mysterious, sorrowful, depressive, serious \\
\hline white & pure, bright, clean, simple \\
\hline grey & low-key, blurry, simple, elegant \\
\hline
\end{tabular}

Relatively speaking, young people or person who more lively and cheerful prefer to red, orange, yellow, green and other more vibrant colors, while older or someone is quiet and peaceful prefer to the cool color such as blue, purple and no-color such as black, white and grey.

3.2.2 The Generation Factor of Color Psychology and Preference

(1) Age (Li, 2012)

Color psychological contrast is particularly evident in the age, psychological requirements of each age is different, so the color requirements are also different. Had mentioned above, children are more prefer high purity and tall lightness color in accordance with their psychological characteristics of pure bright. For most young people, they all have positive and pure psychological, so prefer to bright, lively, strong contrast color. But there is also a part of young people eager to step into society early, has a mature temperament and stable income, so their pursuit of clothing color would prefer to no-color such as black, white, prey and some dark tone. And middle-aged people should pay more attention to the connotation and prefer to choose the low-key with low purity and low lightness highlight generous and elegant. The elderly clothing psychology also has the performance of the two extremes, a kind of elder think they are old and do not very suitable to dress gorgeously, they likely to choose plain dark color to reduce their presence. And another kind think they should take the advantage of the old age time to live for themselves,such as take part in many social activities, so they often choose high purity colors to increased their self-confidence.

(2) Career

Different careers also have different requirements on dress colors due to the different nature of work and faced crowd. For instance, the doctor, always wear white or blue uniform to keep a quiet working environment and make patients 
calm down. The traffic police or sanitation workers usually requires to wear the uniform with high brightness of the fluorescent yellow or fluorescent orange which have eye-catching and reflective effect, because their basic work site is located in the road traffic, and the working hours are often before the morning or after dark with the higher dangerous coefficient.

(3) Somatotype

Black and dark tonal can give a sense of contraction while white and light color tonal express expansion. So as usual, people on the heavy side are more willing to choose black and dark tonal clothing let oneself looks thinner, while a petite one more slant to white and light colored clothes to appear more plump, thus highlighting its sense of presence.

(4) Complexion

The choice of clothing color basically depends on moderate relationship between skin color and clothing color (Pang, 2008), moderate means clothing color can help skin become rosy and shiny looking, instead of dim and dark. Everyone has different complexion by the influence of the genetic and living environment, so everyone has their own appropriate clothing color. Generally speaking, the person with white and light complexion almost have no limitation in choose clothing color, but person with slants black complexion should try to avoid the taller lightness color, so as to avoid sharp contrast make color of skin looks more dark.

\section{Conclusion}

Long-term productive labor and social practice make the adequately improvement of human visual perception ability, so visual merchandising receiving much attention by the merchants. As the most important part of visual merchandising, the display color design should fully follow in line with two important principles, conform to the brand positioning and cater to consumer psychology, then can we performance in brand image well and improve the sales at the same time.

\section{References}

Bian, Z. G. (2010). Study of the path for brand image to upgrade brand core values. Unpublished doctoral dissertation, Shandong University, Shangdong.

Hu, Y. P. (2012). Exhibit display and visual design (pp. 6-14). Tsinghua University Press.

Li, C. D. (2004). Design aesthetic (pp. 106-107). Anhui arts press.

$\mathrm{Li}, \mathrm{S}$. (2012). Consumers color preference and terminal color application research. Unpublished doctoral dissertation, Zhejiang University of technology, Zhengjiang.

Li, Y. Y. (2009). Clothing display color design in the store environment. Journal of art and design, (8), 100-102.

Ma, D., \&Wang X. C. (2006). Goods is king. China Textile \& Apparel Press.

Mu, Y., \& Pan, L. (2014). Clothing display designer tutorial. China Textile \& Apparel Press.

Pang, Q. (2008). The clothing color design. China Youth Press.

Sun, Y. H. (2013). The application research of color elements in children's wear display. Journal of textile industry and technology, 3(162), 80-81.

Tian, J., \& Wang, H. W. (2008). Color psychology and clothing. Journal of chongqing university of industry and commerce, 25(3), 336-338.

Yang, M. H. (2012). Color design in the application of business men's brand goods terminal display. Journal of textile industry and technology, 9(2), 44-53.

Zhou, F. F. (2012). Application of color design in clothing products display. Journal of textile industry and technology, 9(5), 57-68. 